This item was submitted to Loughborough's Research Repository by the author.

Items in Figshare are protected by copyright, with all rights reserved, unless otherwise indicated.

\title{
Extreme case (re)formulation as a practice for making hearably racist talk repairable
}

PLEASE CITE THE PUBLISHED VERSION

http://dx.doi.org/10.1177/0261927X15586573

PUBLISHER

SAGE @ The Author(s)

VERSION

AM (Accepted Manuscript)

\section{PUBLISHER STATEMENT}

This work is made available according to the conditions of the Creative Commons Attribution-NonCommercialNoDerivatives 4.0 International (CC BY-NC-ND 4.0) licence. Full details of this licence are available at: https://creativecommons.org/licenses/by-nc-nd/4.0/

\section{LICENCE}

CC BY-NC-ND 4.0

\section{REPOSITORY RECORD}

Robles, Jessica. 2015. "Extreme Case (re)formulation as a Practice for Making Hearably Racist Talk Repairable”. Loughborough University. https://hdl.handle.net/2134/20703. 
Extreme Case (Re)formulation as a Practice for Making Hearably-Racist Talk Repairable

Jessica S. Robles ${ }^{\mathrm{i}}$

' University of Washington, Seattle, Washington

Corresponding Author:

Jessica S. Robles, Department of Communication, University of Washington, 102 Communications Box 353740,

Seattle WA, 98195

Email: roblesj@uw.edu 


\begin{abstract}
This paper investigates the interactional organization of racism through participant production and uptake of explicit racial membership categories across a corpus of 50+ hours of audio/videorecorded interaction in three U.S. states. The discourse analysis examines one participant method for addressing "hearably racist” talk: echoing extreme versions of the problematic utterance to provide opportunities for repair work on inferable associations between membership categories and category-bound activities. Orienting to implicit inferential material as the source of trouble licenses participant account-seeking; treating the racism as a repairable downgrades its status as an overt instance of racism.
\end{abstract}

\title{
Keywords
}

Racism, membership categorization, extreme case formulations, repair, conversation analysis, grounded practical theory 
Communication is proffered as the solution to a variety of social problems. Parents are told to "talk to your kids about drugs”"1 (Craig, 2005). Youths are encouraged to "use your voice” and “speak up”2 in bullying situations (e.g., Bhat, 2008). “Just say no"33 is a common strategy urged for refusing drugs or unwanted sexual advances (Kitzinger \& Frith, 1999). And advice about responding to racist comments not only suggests there is an obligation to reply ${ }^{4}$, but that replies should convey disapproval and question speakers' reasoning ${ }^{5}$. Yet these well-intended admonitions often fail to account for how people actually interact and the multiple (at times contradictory) functions that talk serves. For example, Kitzinger and Frith (1999) showed that refusals are complex conversational actions accomplished by many tactics besides saying "no"; and van Dijk (1992) illustrated how talk about race makes racist identities salient. Studies such as these demonstrate that the societal ideal of directly addressing social problems can be at odds with how and why talk unfolds in particular ways.

This paper takes a discourse analytic approach to interpretations of racism in ordinary conversation. Two difficulties in pinning down "racism"—-for participants and analysts—include (1) explicitly racist stances are rarely espoused, indeed, potentially racist discourse is often delicately introduced; and (2) “calling out” or otherwise obviously disaligning may be dispreferred, sanctionable, or face-threatening (e.g., van Dijk, 1992; Stokoe, 2015 [this issue]; Whitehead, 2009; Whitehead, 2015 [this issue]). This paper analyzes examples in which participants explicitly name a racial category, associate it with a negatively-assessed activity, and they or their interlocutors orient to that as problematic.

Drawing on conversation analytic membership categorization analysis (Stokoe, 2012; Bushnell, 2014) and grounded practical theory (Craig \& Tracy, 1995), the analysis describes a practice deployed in response to naturally-occurring possibly-racist talk in recordings of private 
face-to-face conversations. The practice involves jokingly taking the hearably racist utterance seriously/literally and reformulating it back to the speaker in such a way that it (1) presents the most extreme or saliently problematic version of the stance espoused, (2) surfaces and calls into question speaker assumptions, and (3) offers the speaker the opportunity to "re-hear" what they said and how it could be interpreted, providing opportunities for accounts and repairs. This practice reveals how participants manage competing interactional exigencies including interactional progressivity, face concerns, moral demands to address racist-sounding talk, and maintaining relationships with others.

The next sections review literature on interactional approaches to racism and relevant concepts. The sections thereafter describe the methods and present illustrative examples from the analysis. The final section considers limitations, implications, and future directions.

\section{Constructing Race in Interaction}

Racism has been an important academic topic especially in critical/cultural studies and social psychology research. Discourse analytic research focuses on how race is constructed and negotiated in text and talk. Critical discourse analysts, who examine how discourse constructs and distributes power relations, ground racism and marginalization practices in discursive strategies (especially those of elite speakers), while conversation analysts focus on how references to race are brought up and taken up in ordinary speakers' talk (c.f., Tileaga, 2005; Whitehead, 2009). Rather than defining racism analytically, the latter examines how participants orient to talk as possibly-racist and how this is negotiated across sequences of situated actions. As with other research on -isms (e.g., Speer \& Potter, 2000: heterosexism) in discourse studies, these approaches can also be contrasted with research that situates prejudice in psychologically- 
based attitudes. Inspecting actual practices and strategies in everyday conversation can yield important insights into how—and potentially why—people might profess problematic stances in private conversations (c.f. Kurylo \& Robles, 2015).

Membership categorization is an area of research relevant to analyzing uses of racial categories in talk. Sacks' (1992) membership categorization device described how member categories are applied in interpretation. In instances of talk, categories function as categories when they are used to do categorical work, that is, to categorize people and/or their activities. Not every description which could be a category necessarily accomplishes this. One way categories work is through association with category bound activities (CBAs). CBAs are activities demonstrably associated with categories such that the category is interpretable because of the activity, or vice versa. For racial categories, a CBA is constructed when participants associate a race categorically (essentially/causally/naturally, etc.) with a particular activity— what might be termed traits/beliefs/behaviors.

For example, in the following excerpt Greg describes a lottery winner. He uses several potential category terms (“lady,” "82," "black”), only the second two of which are mobilized to do category work, and only the last of which will require attention here: specifically, Greg describes the person with the racial category "black."

Excerpt 1 The Lottery [NH Corpus 2012]

1 Greg: so the lady that won she's from Rhode Island she's

2 fucking eighty-two.

3 Kelsey: ei: ghty two she's go:ing to die: (( in a wailing 4 tone))

$5 \rightarrow$ Greg: she won three hunnerd million and she's black (.) so

$6 \rightarrow \quad$ you know she's gunna buy (.) like (stupid) shit,

$7 \quad$ Kelsey: ((stretching noise)) 
Greg asserts that the lottery winner will buy "shit" or items that might be deemed worthless (lines 5-6). This activity is causally linked to race: the "so" stands as a kind of "therefore" or upshot (Raymond, 2004) (line 5). The use of expletives and assessment "that’s fuckin gay" display a negative stance toward the lottery winner's identity and its implications (lines 2, 6, 8), and invite agreement from the interlocutor (line 8), which she provides (line 9). Colloquially, associations between racial categories and activities are the stuff of stereotypes—assumed links between a person's race and what they do—as well as prejudice and racism. This is especially the case when the proffered CBA is negatively assessed.

Participants' discourse is "possibly racist” in part if interlocutors treat it as such. In the prior example they don't, but this is rare. Racist discourse is dispreferred (Stokoe, 2015 [this issue]; Whitehead, 2015 [this issue]), perhaps partly because it is seen as a product of a racist person. This makes “sounding racist” a face-threatening event where face is a person's desired identity/presentation of self (Goffman, 1967). Racism and attributions of racism are therefore delicate matters to be handled carefully. van Dijk (1992) for example describes strategies through which ordinary citizens, elite members of society, and media texts attempt to save face and deny racism in situations where racism could be attributable or is attributed. Such strategies seek to avoid or discredit interpretations of racism, making it difficult for interlocutors to address (let alone challenge) possibly-racist assertions and assessments.

\section{Responding to Racist Discourse}

Whitehead and Lerner (2009) note the importance of examining "the mechanisms through which racial structures are reproduced in individual episodes of interaction, regardless of whether or not 
the discourse being produced therein is judged as 'racist'” (p. 614). This paper’s analysis focuses on moments in which race categories are oriented to as problematic (if not directly called out as racist). This entails looking at how racial categories are produced and when they are taken up as suggesting a possible stereotype or evincing a possible racist stance.

Possible stereotypes/racism makes accounts relevant. Accounts are responses to trouble seeking to explain/give reasons to protect one’s face (Buttny, 1993). van Dijk (1992) describes how participants attempt to deflect racism attributions using accounts before or after a hearablyracist utterance, for example, explicit denials in disclaimers (“I’m not racist, but”) or personal stories as evidence for the stance being a truism. Other research shows how reframing racist stances as ordinary or reasonable attempts to account for racist discourse and construct the meaning of talk as “not (really) racist” (e.g., Figgou \& Condor, 2006; Tileaga, 2005).

Repair is another way participants manage possibly-racist meanings. Repair addresses troubles/errors in speaking, hearing, and understanding (Schegloff, Jefferson \& Sacks, 1977). Repairs can be initiated by speaker or recipient (sometimes both) of the trouble-source turn, and may be accomplished through actions such as repeating, providing a candidate upshot, or asking “what?” Producers of racist talk may initiate and enact repair to suggest what they said was accidental or not meant as it was said. Recipients of racist talk can also request and enact repair on others' talk as a way of eliciting revisions of and/or accounts for what was said. Since racism in general and repair by others in particular are conversationally dispreferred, this poses a double challenge for participants.

Tracy and Ashcraft (2001) define interactional dilemmas as situations where choosing certain ways of speaking to achieve one goal interferes with achieving another, equally-desirable goal. Racism in discourse offers interactional dilemmas for participants because often, ignoring 
the hearably-racist utterance is not an option; however, addressing it is dispreferred in various senses (c.f., Billig, 1988; Figgou \& Condor 2006). A further challenge is that racism, as a function of membership categories, is like those categories what Sacks (1992) called "inference rich,” depending on unstated assumptions (culture). Participants may not always know why something "sounds racist" or may not always be able to explain the basis of categorizations. This makes it hard to ask about and hard to talk about. Bringing inferential material to the surface is, therefore, one way participants can put interpretable racism "on the record," and doing so without apparent rancor avoids direct face threats. This is not to suggest that suppression is the most common (or normatively expected) response to racism—-though publicly disavowed, (Billig, 1988; Condor, Figgou, Abell, Gibson, \& Stevenson, 2006; van Dijk, 1992), in private conversation racist comments may be accepted or unchallenged (and therefore potentially maintained/reinforced) (e.g., Kurylo \& Robles, 2015, which examines some of the cases taken up in the current paper).

Surfacing possible racism may make racism relevant, but may be done in service of courses of action that have no intention of treating the racism seriously. This paper's analysis examines a practical resource that exploits this ambiguity, called here "extreme case reformulation.” This concept builds on Pomerantz's (1986) description of extreme case formulations (ECFs), in which participants use upgraders such as "all” "every” "nothing” "totally" and so forth to intensify a description/assessment. ECFs may defend claims or counter possible criticisms. For example, the phrase “everybody’s doing it” suggests a particular activity is common/normal. Responses to ECFs may accept or challenge them, and in the case of the latter the speaker may thence downgrade intensity. Edwards (2000) notes that speakers orient to the rhetorical force of ECFs and that quoting or echoing ECFs may accomplish exaggeration, 
teasing, and irony. Repeated EFCs do not necessarily do serious disagreement, but can be a form of provocative banter that calls into question the literalness of or investment in an utterance.

In this study's analysis, the sequential position of the ECF comes in the response-to-apossible-description/assessment slot, serving as the provocation itself. It is here called a reformulation because it also repeats, partially repeats, or recycles a hearable “gist,” analogous case, or possible upshot of the previous problematic turn. Repeating, imitating, or offering a candidate upshot of a prior turn also serves as a way of initiating repair or making repair relevant (e.g. Kasper, 2004) since it halts the sequence to draw attention to the clarity/particulars of what was said in an action otherwise sufficient for a next turn. While also a form of "mocking," these repeats are delivered playfully or teasingly and appear not to be designed as a serious challenge or argument initiation; however, they serve as a resource for managing the interactional troubles posed by more serious confrontation.

\section{Data and Methods}

This paper describes a particular environment where racial categories arise and become relevant as potential instances of racism, as well how these are handled in interaction. The data were gathered as part of a large ongoing collection of audio/video recordings including home movies, interviews, and ordinary interaction in three U.S. states across nine years (California, 2004-2006 and 2008; Colorado, 2008-2011; New Hampshire, 2011-2013). The majority of the 50+ hours of data formed the basis of dissertation research on morality in everyday interpersonal communication (Robles, 2011). Originally, instances in which race was made relevant were gleaned from already collected-and-transcribed data for teaching examples; as the collection grew, interested students submitted new data based on interviews and conversational techniques 
designed to elicit/topicalize race. The focal collection includes 26 instances from 16 recordings/conversations. All instances were transcribed according to Jefferson transcription conventions.

These instances include all explicit references to racial categories (including pejoratives/slurs) which occur in three kinds of conversational contexts (categories arising spontaneously in the conversation, categories occurring in a topicalized discussion of race, and categories used in interviews about race). For the purposes of this paper, seven examples were relevant and six are described herein (two in detail). These examples illustrate the range of a particular practice present in a particular sequential environment. Specifically, the contexts are those in which racial categories "come up" rather than being part of a topic or asked about in an interview; the situations are those in which the racial category is treated as problematic in its uptake; the racial references include descriptions of both generalized non-present others and specific present participants; and the practice involves extreme case (re)formulations which will be described in the analysis.

The analysis joins an ethnomethodological interest in the moral underpinnings of interaction and a conversation analytic focus on sequence to examine racial categorization practices in conversation. This perspective explicates participants' procedures for articulating and managing invoked race terms in conversation, focusing on how these terms are made relevant and then in various ways operated on turn-by-turn across participants' situated actions. The racial categories deployed are linked to participants' inferences and assumptions through the application of membership categorization analysis, which uses Sacks' (1992) concept of the membership categorization device to track how categories are used and associated with certain activities. This paper draws on Stokoe's (2012) description of how membership categorization 
and sequential (CA) analysis can work together to produce a systematic account of how categories are put to work in interaction.

The analysis is interested in procedures for constructing of race in talk, but also in understanding and reflecting on the practical challenges of talking about race in interaction. Therefore, the paper's analysis is inspired by the framework of grounded practical theory and discourse analytic methods which explicitly seek to inform and potentially improve communication practices (i.e., action implicative discourse analysis: Tracy, 1995, 2011). Grounded practical theory and resonant discourse analyses ground analysis of practical problems in participants' discourse, investigate how participants attempt to address those problems in their interactions, and reconstruct the practice and its ideals on that basis. This paper analyzes participant techniques for responding to possibly-racist discourse and reconstructs extreme case reformulation practice as a resource that makes manifest certain ideals. The next sections discuss how racial categorizations arise and are oriented to as problematic by speaker and/or recipient; the sort of reformulation and recycling the recipient does in responding; and how these function as techniques to surface and promote possible repair on the category extent and/or reasoning of the CBA.

\section{Orienting to Possibly-Racist Talk}

This section discusses how racial categorizations arise and are dealt with by speaker and recipient. The first example displays a number of features common in the instances which were analyzed in this project. This portion of the exchange occurs after Christa and Val have been discussing having made paper maché globes in school, and Christa jokingly suggests they could make some now and sell them at a flea market. 


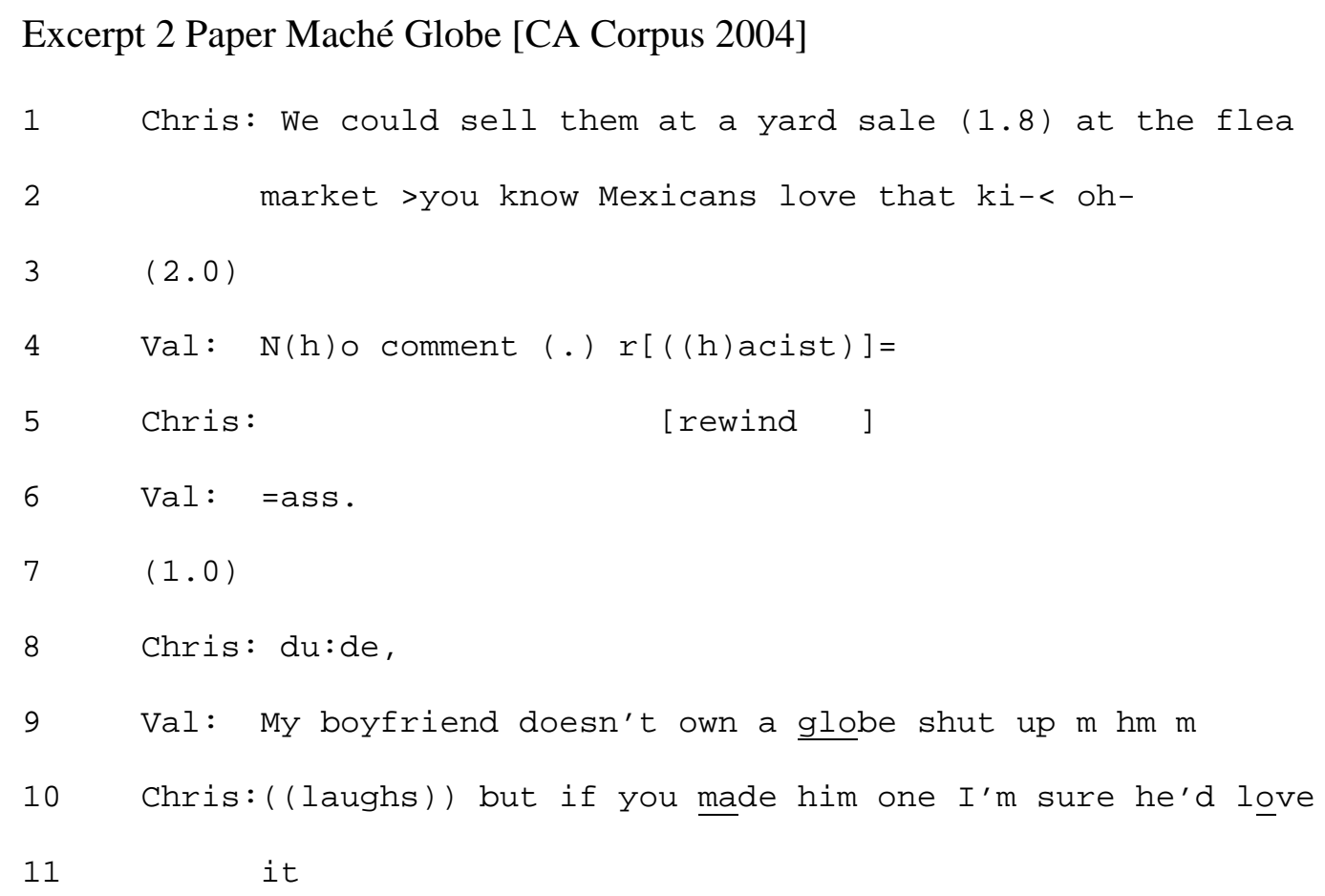

Christa’s self-initiated self-repair serves to display that she has “caught” herself in saying something that could sound racist (line 2; also confirmed by Val's probably mock-insult in lines 4 and 6). Here, the category association between "Mexican” loving yard sales, flea markets, and (ostensibly) what could be purchased from flea markets displays both a negative assessment (what follows and the object or "globe" under discussion illustrates that loving flea markets and flea market wares is not a desirable activity) and signs of trouble in uptake as well (line 4). Val's “no comment” and disalignment could function as account-seeking, inviting Christa to address what she has said, or as other-initiated repair inviting her to withdraw the description, revise her assertion, or in some other way lessening the offense.

Val's turn in line 9 shifts to a different tactic by appearing to take on Christa's claim about Mexicans in general while simultaneously refuting it regarding her boyfriend in particular. This approach bears some resemblance to the practice examined in more detail in the next 
section, and while it is not exactly the same, it functions similarly to challenge the CBA, in this case by testing its limits or extent. Christa responds by changing the projection of her action from one of potential mockery (that Mexicans would like a paper maché globe) to emphasizing the behavior of a specific Mexican person, Val’s boyfriend, as positively receiving the object were Val to give him such a thing (line 10-11). Both women then imitate Val's boyfriend's possible responses to the globe using parodied Mexican accents (not shown in excerpt). Val seems to be provisionally buying into Christa's stance on Mexicans or tacitly accepting it (at least after the initial, albeit joking, sanctions) not because she necessarily disagrees with the CBA itself, but with its application to a particular person. The following examples focus on a practice that challenges the CBA.

\section{Extreme Case Reformulation}

This section examines reformulation and recycling recipients can do in response to hearablyracist talk. In these cases, as in the previous section, recipients seem to "take on" the category association (and possible stereotype) non-seriously, while doing so in such a way as to question the CBA's extent or underlying reasons. The examples analyzed in this section accomplish this through ECFs that repeat the trouble turn or its hearable upshot back to the speaker as a way of making the interpretable racism explicit.

In the next two excerpts from a conversation among three college-age women, Jill attributes the category “Mexican” to Christa (same Christa as in previous section’s example) on the basis that Christa has (and apparently enjoys) a cup of McDonald's sweet tea, which is sitting on her coffee table. Excerpt 3 starts right after JR (the author ${ }^{6}$ ) has done a noticing of the McDonald's cup followed by Jill’s assessment that McDonald's is “evil.” Christa then accounts 
for the presence of the cup by explaining that it contains sweet tea which is "pretty good actually” (line 1).

Excerpt 3 Sweet Tea [CA Corpus 2008]

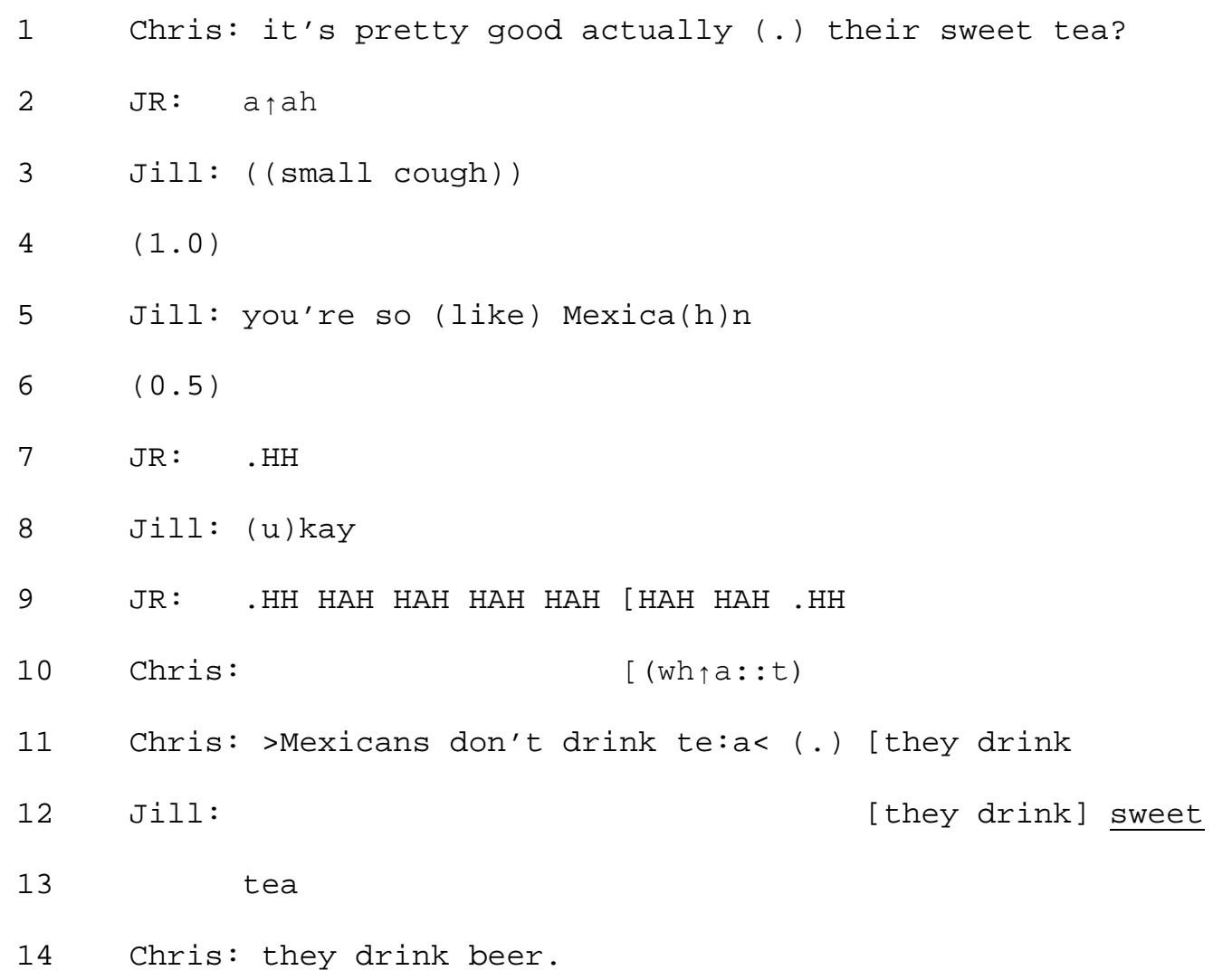

The repair occurs after a period of silence (line 4), a sharp in-breath (line 7), an emphasis ("kay" =“okay”: line 8) and laughter (line 9). “Mexican” is here used to attribute an activity (drinking sweet tea) to Christa (who is not Mexican) (line 5). Though it is not clear whether Jill is negatively assessing this activity, Christa displays disagreement with the association and with its attribution (line 11). The conversation is continued below.

Excerpt 4 Sweet Tea [CA Corpus 2008]

11 Chris: >Mexicans don't drink te:a< (.) [they drink

12 Jill: [they drink] sweet 
14 Chris: they drink beer.

15 Jill: [you know- ]

16 Chris:[(I'm just)] ${ }^{o}$ southerno ${ }^{\circ} h$

17 Jill: a:(h)ll t(h)ey drink $i(h) s$ be(h)er $(0.5)$ the

18 morni: : ng=

$19 \mathrm{JR}:=. \mathrm{H} \cdot \mathrm{H} \cdot \mathrm{H} \cdot \mathrm{H}=$

20 Jill: [=(with) ( ) ]

21 JR: [with the morning's] ne(h)wspaper: hh=

22 Jill: =They don't rea:d heh heh heh heh heh heh heh. hh

23 Christa: ०I didn't say that。

$24(0.5)$

25 Jill: $A(h) l l$ of the commercials $I^{\prime}$ ve seen for the sweet tea have been Mexicans and all of the ads have been

27 in Spanish=

28 Chris: =I don't think- everything's in Spanish

Christa's disagreement is followed by repairing the CBA to Mexicans drinking beer rather than sweet tea (line 11 and 13) (she also repairs the category attribution of herself to “southern” as an explanation for drinking sweet tea: line 16). Trouble is evident earlier in the gasping laughter (line 7 and 9), and Jill and Christa display disagreement over both category associations each has made (that Mexicans drink sweet tea or beer). Christa's treatment of Jill's categorization appears to be primarily "personal”- the trouble is that Jill has attributed the category to her-while Jill and JR's response to Christa focuses more on the category deployment in general; this analysis focuses on the latter.

Jill and JR mock Christa’s association between Mexicans and beer consumption by voicing the position in extreme case reformulations of what Christa has apparently espoused. Jill 
says, with laugh particles, "all they drink is beer" and adds "in the morning” (line 83). By using the term "all” Jill makes explicit that Christa's statement “they drink beer" implied that they must do this to the exclusion of other drinks, such as sweet tea. This is similar to another case in the data in which a participant disagrees with another's claim of having German and Irish background because his having a Japanese background excludes all possible others.

Both references in the example ("all" and "in the morning") can be considered unusual or unlikely, as drinking only beer and drinking in the mornings is associated with alcoholism or caricature. JR further emphasizes the ridiculousness of this by suggesting they would drink beer while reading the morning newspaper (also laughing) (line 84), which Jill follows with "they don't read” (line 85). This can be seen as upgrading the negative assessment associated with joining "Mexican” with "drinking beer," implying that the assumption that Mexicans only drink beer would be as unreasonable as assuming they do not read. That Christa hears it this way is evident in her quietly-spoken next turn, “I didn’t say that” (line 86). Formulating it as something she did not say also suggests she "hears” Jill's and JR's performances as “doing” what she had previously been saying—as, in essence, playing a more extreme version of her. Jill then provides her own account for her initial association between "Mexican” and drinking sweet tea (lines 8890), perhaps as another way of distinguishing what she said as more reasonable than what Christa said. Christa does not explicitly repair what she had said and implied, but saying “I didn’t say that" suggests that she sees the positions being attributed to her as too extreme. This could be a subtle way of downgrading what she meant.

There were several examples like this in the data, for instance, a speaker qualifies "Indians” with "loud," prompting voicings from participants about "quiet American tourists” and resulting in the speaker clarifying that the Indians she was talking about were loud, but not that 
she meant all Indians were loud. These sorts of reformulations serve a reverse function to the typical extreme case formulations Pomerantz (1986) describes: rather than asserting something to defend oneself, they over-assert in such a way to indicate the opposite, to challenge someone else. In other words, while ECFs legitimize claims by suggesting a particular description, activity, or stance is normal or reasonable, extreme case reformulations do the opposite by taking a stance so far as to suggest it is not reasonable (see also Edwards, 2000). In the previous examples described, the content being worked on involves the extent of the association between the category and the activity.

Directly challenging the trouble-source turn on "degree of facticity" could involve asking, for example, “do all Mexicans really like flea markets?” or “why do you think Mexicans only drink beer?” Such questions would have made relevant some account for the position. They would also have been more face-threatening, more disruptive to the progressivity of the focal action underway, and more explicitly argumentative. Instead, repeating and drawing out the inferences of the CBA makes visible what is problematic about it without stating it outright, and doing so in a joking tone lessens the face-threat. This practice of ECFs as a technique to test the extent of the CBA appears to be designed to elicit repair on the existence or strength of a CBA, with one systematically possible outcome being that of getting the speaker of the trouble-source turn to downgrade what they have said. This would function to remove or lessen what is hearable as a problematic association between a race category and a negatively-assessable category. Providing speakers this opportunity can allow for a "quick-fix" of the racist talk which does not halt progressivity for too long if the speaker complies and repairs. The recipient can address the moral impetus to acknowledge racist-sounding talk while maintaining myriad other interactional goals. 
Extreme case reformulations were sometimes used to surface slightly more complex relationships between categories and activities, including not just the extent of the CBA but also its underlying reasoning. This appeared to be a more delicate project, for several reasons. Firstly, challenging reasons relates to deeper inferential matters which are not only unstated, but may be hard for participants to articulate. Secondly, articulating these opens up possibilities for misunderstanding and disagreement among interlocutors. Thirdly, these can cause trouble between participants and potential progressivity derailments. Perhaps for this reason this technique was rarer and almost always occurred in interviews or cases where race was previously topicalized. The following example is the only one that occurred in a similar conversational context as those focused on in this analysis (spontaneously arising categories). In this example one of the participants has been discussing her living situations. When the category "Chinese" is mentioned, the speaker self-repairs and displays signs of trouble with the association between "Chinese people" and a strange or unpleasant odor (line 10). Though she further explains that what she means is the food that the Chinese people in her dorm cooked (not the people themselves) (line 22), the other participants jointly produce a mirroring CBA and assessment. Excerpt 5 Smells Funny [NH Corpus 2013]

1 Selina: I'm s:o excited not to live with girls ne- er 2 anybody (. ) next year,

3 Geoff: where're ya- (.) livin=

4 Selina: (uh ka ku) [( )]

5 Bill: $\quad\left[\left({ }^{\prime}\right)\right]$

6 Selina: ( ) and I have to live in a $\mathrm{fr}(\mathrm{h})$ eshman dorm=

7 Geoff: =huh huh=

8 Selina: it's (hard cuz I'm gonna live) right next to 


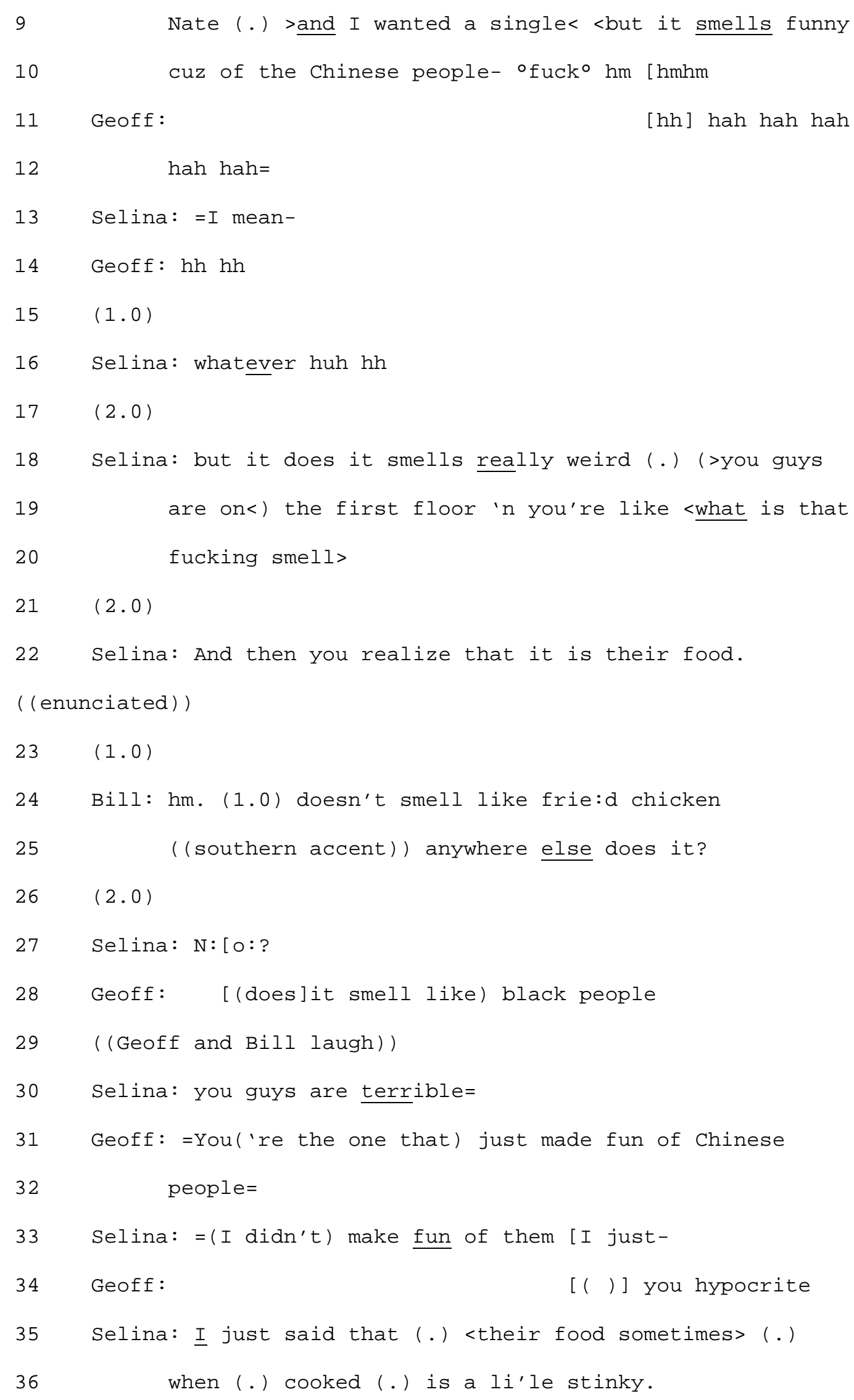


38 Selina: SHUT UP

$39 \quad($ (laughter $))$

Selina displays understanding with the trouble with what she’s said and does repair (line 10, 13, 22), but Bill and Geoff pursue the matter further. Bill's introduction of another food smell (fried chicken) (line 24) prompts Geoff to supply an association with another race category stereotypically linked with fried chicken (black people) (line 28) while simultaneously producing an association analogous to one interpretation of Selina's first mention: that the people, not the food, is the source of the smell. It is unclear whether Selina's response is aimed at the content of their talk or its function to tease her (line 30), but Geoff seems to take it up as content-related in order to return to her earlier comments (line 31-32, 34). This suggests that his and Geoff's turns serve as further repair, account, or teasing pursuits on Selina's comments, and that she has not explained herself or displayed sufficient awareness of the problematic nature of her utterance.

Bill's and Geoff's analogous but more saliently problematic scenario imitates and reformulates a version of what Selina said. The "extreme case" here is not built out of intensifying words, but rather out of shared cultural knowledge in which the category of "black people" has historically been associated with public and media discourse about racism in the United States. In comparison to the previous examples, this version of the practice is also different because it is not just repairing the association between a category (such as Chinese or black people) and an activity (being smelly/having smelly food): additionally, it makes visible that even if Selina is talking about food and not people, there is still something problematic about the association, in which case it requires more than just a repair of what was meant, but a further examination of what the problem is. Because in this case the pursuit is dropped, it is unclear 
what more was being pursued, exactly. In the context of an ordinary conversation in which race "arises" but is not a topic, this sort of eventual dropping of the subject is common in these cases. It could be the case that just getting the speaker to notice and display noticing is sufficient, or that the teasing was never intended to require a serious response.

\section{Making Racist Discourse Repairable}

Public discourses abound with advice and assumptions about what racism is and how it should be addressed. However, in focusing primarily on the moral imperative to address racism, these discussions tend to advise practices at odds with other considerations in everyday interaction, including progressivity, relational, and face demands. The previous sections described a practice for responding to hearably-racist talk after evidence of trouble. This practice served as a resource for attending to multiple interactional demands and involved reformulating an extreme case of the problematic utterance or its upshot by doing a partial repeat with intensifiers or supplying an analogous extreme case. In former, the practice was deployed as a technique for questioning the extent of the CBA in such a way as to make repair relevant; in the latter, the practice was deployed as a technique for questioning the reasoning behind the CBA in such a way as to make repair, accounts, and/or salience of the problem potentially relevant.

Pomerantz (1986) concludes three points in her article on extreme case formulations: that ECFs "assert the strongest hearing," are addressed to the "cause of a phenomenon," and concern the "rightness (wrongness) of a practice" (p. 227). This is true of the practice described here as well. Taking up an extreme case reformulation of the utterance or upshot of racist-sounding talk was a way of performing the "strongest hearing" of the utterance back to the speaker; could be deployed to test the strength or intensity of a claim as well as its underlying assumptions, 
including "cause"; and called into question the rightness of the trouble turn. In classical logic/argumentation scholarship, this could be considered a form of reduction ad absurdum: a strategy of displaying the absurdity of an argumentative position by pushing its premises, conclusions, or consequences to their limit.

Basing this on faulty premises would traditionally be considered fallacious (in examples such as ad hominem and "slippery slope" arguments) (Walton, 1993), and one can imagine that in different circumstances the speaker of the racist-sounding utterance could refute the validity of the challenge in the first place. This rarely occurred in the data (though see excerpt 4 line 23, "I didn't say that" as a possible instance), perhaps suggesting that all participants shared enough of a frame of reference to assume that pushing their statement to its "logical conclusion" was by and large a reasonable thing to do; or because it was clear that the challenge was joking or nonserious. It could also indicate that participants treat the attribution of racism as a matter of principle rather than a matter of degree: in other words, racism is not a scalar quality and one cannot be "a little bit racist.”

That the practice described herein did not result in strongly face-threatening or argumentative interaction speaks in parts to its success in attending to multiple interactional goals. On one hand, it fulfills the moral obligation to respond to racist-sounding talk by bringing the hearably-racist content onto the record and making it available for uptake. Furthermore, it overwhelmingly seems to treat the possible racism as a fixable feature of the discourse rather than an attitude of a person. This point, alongside with its teasing and non-literal performance, could be problematic from a critical perspective, a way of avoiding taking a serious issue seriously. 
Though using the practice to surface more complex inferential material was rarer across the data (especially when racial categories spontaneously arose), testing the extent of the CBA was common across cases given the condition that participants were familiar with one another. For instance, in the following example race was topicalized in an "interview-style" discussion among friends. Jimmy admits (lines 1-8) that he believes stereotypes can be based on fact and in line 9 Megan reformulates an extreme case of Jimmy’s prior (expanded in line 11).

Excerpt 6 True Stereotypes [NH Corpus 2012]

1 Jimmy: <from yah true stereotypes and from-from things that

2 I've personally seen and-an how a:h certain people

3 like to act based on the color of their skin and

4 think that they can get away with certain things just

5 because they're a certain a:h race and now I'm just

6 racist- I'm not just a:h- not just saying toward a:h

7 black people in general but there's other-other

8 races that $>=$

9 Megan: =I'M RACIST TOWARDS EVERYONE ( (laughs))

10 Jimmy: no I'm just saying that there are=

11 Megan: $=(($ laughing $))=I$ DEFINITELY do not discriminate

12 against JUST black people=

13 Jimmy:=yah well no I don't-

This example and others indicate that this practice may apply across environments, varying internally by what sort of upshot is being explicated (the extent versus the logic of the CBA) and conditioned by the context-here, the private interpersonal nature of the conversations. It would be hard to imagine this sort of practice being deployed in institutional settings.

These conclusions are therefore limited by the data. This corpus is based primarily on naturally-occurring instances of possible racism, which do not often arise. Furthermore, being 
recorded may have had an influence on the repair instantiations and organization, given participants in the examples analyzed knew they were being recorded at the time of recording. Some of the data may not have been typical, as the data evinced a range of positions toward racism and racist discourse. However, examples selected were key ones from a larger set and illustrated a general pattern of methods by which people manage racial references and possiblyracist discourse.

The results suggest some ways in which people might reflect on how to respond to racist discourse in different settings. While the practice of doing an extreme case reformulation may be specific to people with an established prior relationship, the techniques to which it was put are potentially more generalizable. For example, pursuing the fact status and extent of CBAs seems to work well when seeking to briefly highlight something problematic, while pursuing various sorts of unstated CBA instances through humor attends to the face-threat of challenging racism (if not addressing the problem of racism). Future research directions could examine various situated ideals across settings to consider how different repair attempts may or may not be wellreceived.

This analysis described a practice that draws on cultural inferences and is about cultural categories, involving metadiscursive moves in conversation and potentially contributing to a larger societal metadiscourse about the nature of racism and how to talk (or "not really talk”) about it. The practice involves jokingly taking the hearably racist utterance seriously or literally and reformulating/imitating it back to the speaker in such a way that it (1) presents the most extreme or a more saliently problematic version of the stance espoused, (2) surfaces and calls into question the assumptions of the speaker, and (3) offers the speaker the opportunity to "rehear" what they said and how it could be interpreted, providing opportunities for accounts and 
repairs. The analysis described two techniques served by this practice: challenging the extent of the CBA, and challenging the underlying logic of the CBA.

By grounding racism in participants’ turn-by-turn negotiations of glossably stereotypical associations between membership categories and proffered category-bound activities, this analysis described one way in which -isms are produced and challenged in interaction. Results offer insights into why some talk seems racist and how to think about overcoming the challenges of addressing possibly-racist talk.

\section{Acknowledgements}

I thank Kevin Whitehead, Liz Stokoe, and Tanya Romaniuk for their work on the ICCA-14 panel for which this paper was prepared, Karen Tracy and Stephen DiDomenico for comments on earlier drafts, and reviewer insights and suggestions.

\section{Author's note}

Earlier versions of portions of this paper were presented at the 4th International Conference on Conversation Analysis (ICCA-14) in Los Angeles in June 2014.

\section{Declaration of Conflicting Interests}

The author declared no potential conflicts of interest with respect to authorship and/or publication of this article.

\section{Funding}

The author received no financial support for the research and/or authorship of this article. 


\section{Notes}

1. http://www.drugabuse.gov/publications/marijuana-facts-parents-need-to-know/talking-toyour-kids-communicating-risks

2. http://www.kidpower.org/library/article/preventbullying/?gclid=CI6o2py38r8CFWuCMgodF1YAyg

3. http://en.wikipedia.org/wiki/Just_Say_No

4. http://www.npr.org/templates/story/story.php?storyId=5576785

5. http://www.creativespirits.info/aboriginalculture/people/how-to-deal-with-racist-people\#toc7

6. The author appeared in some recordings before this project existed.

\section{References}

Bhat, C. S. (2008). Cyber bullying: Overview and strategies for school counsellors, guidance counsellors, and all school personnel. Australian Journal of Guidance and Counselling, 18, 53-66.

Billig, M. (1988). The notion of prejudice: Some rhetorical and ideological aspects. Text, 8, 91110.

Bushnell, C. (2014). On developing a systematic methodology for analyzing categories in talkin-interaction: sequential categorization analysis. Pragmatics, 24, 735-756.

Buttny, R. (1993). Social accountability in communication. London, UK: Sage.

Craig, R. T. (2005). How we talk about how we talk: Communication theory in the public interest. Journal of Communication, 55, 659-667. 
Craig, R. T., \& Tracy, K. (1995). Grounded practical theory: The case of intellectual discussion. Communication Theory, 5, 248-272.

Condor, S., Figgou, L., Abell, J., Gibson, S., \& Stevenson, C. (2006). “They’re not racist...” Prejudice denial, mitigation and suppression in dialogue. British Journal of Social Psychology, 45, 441-462.

Edwards, D. (2000). Extreme case formulations: Softeners, investment, and doing nonliteral. Research on Language and Social Interaction, 33, 347-373.

Figgou, L. \& Condor, S. (2006). Irrational categorization, natural intolerance and reasonable discrimination: Lay representations of prejudice and racism. British Journal of Social Psychology, 45, 219-243.

Goffman, E. (1967). Interaction ritual: Essays in face-to-face behavior. New York, NY: Anchor Books.

Jefferson, G. (1984). Transcription notation. In J. M. Atkinson \& J. Heritage (Eds.), Structures of social action: Studies in conversation analysis (pp. ix-xi). Cambridge, UK: Cambridge University Press.

Kasper, G. (2004). Speech acts in (inter)action: Repeated questions. Intercultural Pragmatics, 1, 125-133.

Kurylo, A. \& Robles, J.S. (2015). How should I respond to them? An emergent categorization of responses to interpersonally communicated stereotypes. Journal of Intercultural Communication Research, 44, 64-91.

Kitzinger, C. \& Frith, H. (1999). Just say no? The use of conversation analysis in developing a feminist perspective on sexual refusal. Discourse and Society, 10, 293-316. 
Pomerantz, A. (1986). Extreme case formulations: A way of legitimizing claims. Human Studies, 9, 219-229.

Raymond, G. (2004). Promoting action: The stand-alone "so" in ordinary conversation. Research on Language \& Social Interaction, 37, 185-218.

Robles, J. S. (2011). The interactive achievement of morality in everyday talk: A discourse analysis of moral practices and problems in interpersonal relationships (Unpublished doctoral dissertation). University of Colorado at Boulder, Colorado.

Sacks, H. (1992). Lectures on conversation. Cambridge, MA: Blackwell.

Schegloff, E. A. (2007). Sequence organization in interaction: A primer in conversation analysis. Cambridge, UK: Cambridge University Press.

Schegloff, E. A., Jefferson, G., \& Sacks, H. (1977). The preference for self-correction in the organization of repair in conversation.

Speer, S. A. \& Potter, J. (2000). The management of heterosexist talk: Conversational resources and prejudiced claims. Discourse and Society, 11, 543-572.

Stokoe, E. (2012). Moving forward with membership categorization analysis: Methods for systematic analysis. Discourse Studies, 14, 277-303.

Stokoe, E. (2015). Identifying and responding to possible '-isms' in institutional encounters: Alignment, impartiality, and the implications for communication training. Journal of Language and Social Psychology.

Tileaga, C. (2005). Accounting for extreme prejudice and legitimating blame in talk about the Romanies. Discourse and Society, 16, 603-624.

Tracy, K. (1995). Action-implicative discourse analysis. Journal of Language and Social Psychology, 14, 195-215. 
Tracy, K. (2011). "Reasonable hostility”: Its usefulness and limitation as a norm for public hearings. Informal Logic, 31, 171-190.

Tracy, K., \& Ashcraft, C. (2001). Crafting policies about controversial values: How wording disputes manage a group dilemma. Journal of Applied Communication Research, 29, 297-316.

van Dijk, T. (1992). Discourse and the denial of racism. Discourse and Society, 3, 87-118.

Walton, D. (1993). Commitment, types of dialogue, and fallacies. Informal Logic, 14, 93-103.

Whitehead, K. A. (2009). “Categorizing the categorizer”: The management of racial common sense in interaction. Social Psychology Quarterly, 72, 325-342.

Whitehead, K. A. \& Lerner, G. H. (2009). When are persons ‘white’?: On some practical asymmetries of racial reference in talk-in-interaction. Discourse and Society, 20, 613 641.

Whitehead, K. A. (2015). Everyday antiracism in action: Preference organization in responses to racism. Journal of Language and Social Psychology.

\section{Author Biography}

Jessica S. Robles is a lecturer in the Department of Communication at the University of Washington, Seattle. Her research uses discourse analysis to examine the interactional, relational, and cultural dimensions of morality in everyday conversations. She is especially interested in the discursive practices interactants employ to manage interactional trouble. She is co-author of the second edition of Everyday Talk: Building and Reflecting Identities (with Karen Tracy, Guilford, 2013). 